\title{
Towards a Business Process Owner Competency Framework
}

\author{
Malcolm Garbutt, Lisa F. Seymour, Alfred Rudman \\ Department of Information Systems, University of Cape Town, South Africa
}

\begin{abstract}
Process owners are vital to the establishment and functioning of process oriented organizations. However, there is a paucity of understanding regarding the tasks process owners should undertake and what competencies they require. In this study, sets of process owner competencies and process owner tasks emerged from interviews with executives from three financial services organizations in South Africa. The findings were compared to the BPTrends report "State of the Business Process Management Market 2016". Common themes were identified and validated against recent literature. Based on the validated themes a business process owner competency framework was developed and discussed. The framework shows that business process owners require competencies in core business process management, strategic alignment, determining organizational goals, governance, documentation, training, and systemic thinking. The competencies and tasks identified provide a practical contribution to practitioners and recruiters in the field, while the framework adds a theoretical contribution to the field of business process management.
\end{abstract}

Keywords: business process monitoring, process owner, process orientation, process owner competencies, process owner tasks

Categories: • Applied computing $\sim$ Business process management

Email:

Malcolm Garbutt Malcolm.Garbutt@alumni.uct.ac.za (CORRESPONDING),

Lisa F. Seymour Lisa.Seymour@uct.ac.za,

Alfred Rudman AlfredRudman@gmail.com

\author{
Article history: \\ Received: 18 Jan 2017 \\ Accepted: 13 April 2017 \\ Available online: 9 July 2017
}

\section{INTRODUCTION}

Business process management (BPM) can assist organizations in sustaining competitive advantage in the marketplace through embracing and implementing best practice management principles, strategies and technologies on a continuous basis (Kohlbacher \& Gruenwald, 2011). BPM is defined as a management practice that integrates business process knowledge and information technology with the aim of transforming business efforts into integrated and measurable cross-functional activities that deliver strategic and operational competitive advantage (Antonucci \& Goeke, 2011). Moreover, BPM holds promise for increasing productivity, achieving operational excellence and saving costs (Recker \& Mendling, 2016). The importance of managing and improving corporate components including process strategy, process architecture, process ownership, process measurement and process

Garbutt, M., Seymour, L.F., and Rudman, A. (2017). Towards a Business Process Owner Competency Framework. South African Computer Journal 29(1), 122-146. https://doi.org/10.18489/sacj.v29i1.454

Copyright (C) the author(s); published under a Creative Commons NonCommercial 4.0 License (CC BY-NC 4.0).

$S A C J$ is a publication of the South African Institute of Computer Scientists and Information Technologists. ISSN 1015-7999 (print) ISSN 2313-7835 (online). 
improvement (Smart, Maddern, \& Maull, 2009) are recognised by many organizations. However, managers of adopting organizations need to understand the implications and impact of process adoption (Kohlbacher \& Gruenwald, 2011).

Process management has turned out to be "much more thorny than envisioned" (van der Aalst, la Rosa, \& Santoro, 2016, p. 3). Efforts to improve business processes have historically been incomplete, focusing on functional automation of processes and utilizing information technology. Exclusively automating processes has limited impact on competitive position due to ignoring end-to-end crossfunctional linkages which are important from a customer retention and satisfaction perspective (Goeke \& Antonucci, 2013). This leads to reduction in end-to-end process control and limited process ownership (Larsen \& Klischewski, 2004) with non-evolving processes and lack of improvement opportunities. Consequently, the appointment of process owners and the implementation of process performance monitoring for process improvement resulting from process initiatives is recommended (Kohlbacher \& Gruenwald, 2011).

While the appointment of process owners is an important aspect in BPM (Armistead, Pritchard, \& Machin, 1999), there is a paucity of empirical studies investigating exactly what the process owner role and tasks entail in practice (Nesheim, 2011). According to Nesheim (2011) tasks are based on primary competencies that should be augmented through learning from specific situations.

Many researchers have identified and called for more BPM research in this area. Business processes have a lifecycle with the last phase being process monitoring and controlling (Dumas, La Rosa, Mendling, Reijers, et al., 2013). It is during this last phase that the process owner role becomes important, yet this phase has received the least research coverage (2\%) in a recent BPM review (Recker \& Mendling, 2016). The same review noted an absence of thorough empirical work that concerns BPM in actual industry practice and expressed a call for more studies covering theory building from case study research and "the description and understanding of human and organizational behavior in the context of managing business processes" (Recker \& Mendling, 2016, p. 66). Yet another study notes the considerable gap between state-of-the-art BPM technologies and approaches and actual usage by BPM practitioners and their needs (van der Aalst et al., 2016).

This research therefore focuses on actual industry practice and practitioner needs and builds a conceptual framework. It has a twofold aim. Firstly, it explores the tasks process owners should be undertaking and what supporting competencies they require to enact such tasks, and secondly, it provides a process owner competency framework. This framework offers practitioners a checklist when appointing and monitoring process owners while affording understanding of the significance of the process owner role.

This paper is organised as follows. In Section 2, a review of the literature is presented and in Section 3, an overview of the research method for the study is provided. Sections 4 and 5 describe the process owner competencies and tasks, followed by a short discussion in Section 6. In Section 7 the concepts in the framework are presented. The framework is then provided in Section 8 and validated against BPM models presented by Hammer (2015) and Rosemann and vom Brocke (2015). Section 9 presents implications for practice and concludes the study.

This paper is a substantially revised and extended version of the Rudman, Garbutt, and Seymour (2016) conference paper. Section 7 of this paper is new and introduces the Business Process Owner 
Competency Framework which shows the interlinked themes which form part of a business process management system.

\section{LITERATURE REVIEW}

Successful BPM implementations necessitate adoption of a process oriented view of the organization. Part of the successful transition to a process oriented organisation entails appointing process owners, establishing BPM and creating governance boards (Goeke \& Antonucci, 2013). BPM governance is required to align systems and practice (Doebeli, Fisher, Gapp, \& Sanzogni, 2011) for which organizational design changes may be required (Armistead et al., 1999) and consequently management of these changes. Continuous process improvement through (re-)alignment with the organizational environment is vital for benefits from BPM (Niehaves, Poeppelbuss, Plattfaut, \& Becker, 2014). Such process improvement must be performed in an active and systematic manner (Kohlbacher \& Gruenwald, 2011). While process improvements can increase staff satisfaction, they have been observed to be critical in driving customer satisfaction, especially in the financial services sector (Kumar, Smart, Maddern, \& Maull, 2008) leading the researchers to conclude that "practitioners should focus on process management... rather than simply addressing service quality from a functional perspective".

Process owners are the most visible difference between process oriented and traditional organizations (Hammer \& Stanton, 1999) and are crucial to the effectiveness of process orientation (Smart et al., 2009; Reijers \& Peeters, 2010). They are viewed as the champions of process and take overall responsibility for process performance being central in interfacing cross-functional processes. Process owners should be appointed on a full-time basis to assist in evolution of processes and to curb the organisation reverting to less effective processes (Hammer \& Stanton, 1999). Hence identification and allocation of process owners to the core business processes is a key element for effective BPM (Kumar et al., 2008). Nevertheless, there is a paucity of empirical research on what process owner should be doing on a day-to-day basis (Kohlbacher \& Gruenwald, 2011; Nesheim, 2011). The fundamental role that a process owner plays entails the management of interfaces between key processes with the objective of preventing horizontal silos. The process owner has overall responsibility of the end-to-end process performance utilizing metrics to track, measure and monitor the status of the business process with emphasis on continuous improvement initiatives (Kohlbacher \& Gruenwald, 2011). Associated with process performance monitoring is capacity planning which requires process owners to ensure that staff are adequately trained and allocated to processes. In practice this may result in conflicts arising between process owners, teams, and functional management (Smart et al., 2009).

Whereas many organizations with BPM programs assign process owners, BPM programs are found frequently to be either ad-hoc or project-based (Reijers \& Peeters, 2010) and consequently without dedicated process owners. While process owners are considered responsible for managing processes little is known about what they are supposed to do beyond assuming responsibility for (a) process performance and (b) process improvement (Reijers \& Peeters, 2010) In the absence of a specific process owner task framework general BPM tasks may be applicable to the process owner role. A literature review, for instance, found three categories of BPM tasks which bear relationship to 
process owners: designing processes; day-to-day management of processes; and fostering process related learning (Paim, Mansur Caulliraux, \& Cardoso, 2008). However, this postulation is not supported empirically. Furthermore, limited knowledge of the tasks that process owners should be performing daily indicates that the competencies required by process owners in performing their tasks are also unidentified. Process owner competencies are understood as the knowledge, skills and attitudes required by process owners to perform business process tasks effectively (Ravesteyn, Batenburg, \& de Waal, 2008).

\section{RESEARCH METHOD}

This study had as its aim the identification of requisite competencies and tasks undertaken by process owners. Primary and secondary data was collected and analysed. Primary data was collected through eleven interviews over a period of two months in 2014 at three financial services organizations in Gauteng, South Africa with whom one author had a business relationship. The study was exploratory and interpretive using semi-structured interviews with four executives, six senior managers and one consultant which were then analyzed in accordance with the general inductive approach (Thomas, 2006). Exploratory research is useful for investigating a new area of inquiry to determine the feasibility of further research of that phenomenon while the interpretive research philosophy is useful to build theory through subjective interpretation of participants' perspectives (Bhattacherjee, 2012). The interviews were recorded and transcribed prior to reading and re-reading. Codes were then assigned to relevant portions of the transcriptions and aggregated into thematic categories. The number of coded empirical text excerpts were counted. The themes were then captured as nodes in Freeplane mind mapping tool ${ }^{1}$. Two high level nodes (Competency and Tasks) were created with up to 3 levels of sub-nodes.

To add extra depth to the empirical study, findings were then compared to a 2015 survey on the state of the business process market (Harmon \& Wolf, 2016). The BPTrends study reports and compares results from similar business process studies undertaken every alternate year since 2005. The 116 respondents were from a broad range of industries across the globe. This secondary data was analysed using a combined inductive and deductive thematic analysis (Braun \& Clarke, 2006). Basic themes were supplied from the empirical study and were used for initial coding although the final themes emerged from the data. Each set of findings were mapped to a node with the relevant findings to sub-nodes. Using the search function in Freeplane sets of terms (theme codes) were searched for. Table 1 lists the categories and the search term/s used. Wildcards were used to find variations of terms.

The next step involved manually checking the mind-map and removing nodes that were irrelevant. The mind map was then copied into a Microsoft Excel spreadsheet and sorted by category, subcategory, detail, and sub-detail matching the four levels determined from the mind map. The spreadsheet was analyzed for patterns and links between the process owner research findings and the BPTrends survey. The identified patterns and findings were then summarised into a conceptual

\footnotetext{
${ }^{1}$ http://www.freeplane.org
} 
framework. The findings are now discussed.

Table 1: Thematic analysis categories and searches

\begin{tabular}{|l|l|}
\hline Category & Search Term \\
\hline Training & Train* \\
\hline Metrics & Metric, Measure* \\
\hline Framework & Framework \\
\hline Improvement & Improvement \\
\hline Change & Change \\
\hline Process Management & Process Management \\
\hline Architecture & Architecture \\
\hline Modeling & Model*, Map*, Graphics** \\
\hline Performance & Performance, Monitor* \\
\hline Customer & Customer \\
\hline Capacity & Capacity \\
\hline Automation & Automat*, BPMS, Tech* \\
\hline Governance & Govern** \\
\hline Alignment & Align*, Strateg* \\
\hline Rules & Rule \\
\hline Documentation & Document* \\
\hline People & Communic*, Interpersonal, People \\
\hline Thinking & Think* \\
\hline Coordination & Coord* \\
\hline
\end{tabular}

\section{PROCESS OWNER COMPETENCIES}

Three competency categories comprising task related competencies; people related competencies; and thinking competencies emerged from the analysis as shown in Table 2. Competencies in the form of knowledge, skills and, to a lesser extent, attitudes emerged from the data within the three categories. The most significant competency set in the study is task related competencies (count $=103$ ), the second most important set of competencies relates to people competencies (count $=34$ ) and the third competence identified is systemic thinking (count $=19$ ). The categories also exhibited considerable interaction between them. Overall the highest ranked individual competencies required by business process owners were found to be sub-categories BPM (count $=79$ ), interpersonal competencies (count $=26$ ), systemic thinking (count $=19$ ) and customer focus (count $=10$ ). The competencies are described and supported by extracts from the interviews in the rest of this section. 
Table 2: Process owner competencies

\begin{tabular}{|c|c|c|c|}
\hline Category & Sub-category & Basic theme & Count \\
\hline \multirow{11}{*}{ Task } & \multirow{8}{*}{ BPM } & $\begin{array}{l}\text { Understanding and practical application of process design and improve- } \\
\text { ment methodologies, tools and techniques }\end{array}$ & 45 \\
\hline & & $\begin{array}{l}\text { Understanding and practical execution of effective process management } \\
\text { principles and practices }\end{array}$ & 8 \\
\hline & & Understanding BPM frameworks, standard and practical implementation & 8 \\
\hline & & Numerical and data analytical skills & 6 \\
\hline & & Understanding of technology architecture supporting business processes & 4 \\
\hline & & Knowledge and practical application of process mapping standards & 3 \\
\hline & & $\begin{array}{l}\text { Understanding and practical implementation and monitoring of process } \\
\text { metrics and measurements }\end{array}$ & 3 \\
\hline & & $\begin{array}{l}\text { Understanding and practical implementation of work demand and staff } \\
\text { capacity planning requirements }\end{array}$ & 2 \\
\hline & Customer Focus & $\begin{array}{l}\text { Understanding and practical application of customer experience expect- } \\
\text { ation of process }\end{array}$ & 10 \\
\hline & $\begin{array}{l}\text { Process Change } \\
\text { Facilitation }\end{array}$ & Change management facilitation and presentation skills & 9 \\
\hline & $\begin{array}{l}\text { Process } \\
\text { Governance }\end{array}$ & Understanding of process governance and risk mitigation activities & 5 \\
\hline \multicolumn{3}{|l|}{ Task Total } & 103 \\
\hline \multirow{7}{*}{ People } & \multirow{5}{*}{ Interpersonal } & Influencing and negotiation skills with personal mastery & 10 \\
\hline & & Effective people management and motivation skills & 7 \\
\hline & & Effective communication skills & 4 \\
\hline & & Creative and innovative thinking abilities & 3 \\
\hline & & Leadership and effective management capabilities & 2 \\
\hline & \multirow{2}{*}{$\begin{array}{l}\text { Organisation } \\
\text { Understanding }\end{array}$} & Understanding of organisational context and culture & 5 \\
\hline & & Understanding organisational design principles & 3 \\
\hline \multicolumn{3}{|c|}{ People Total } & 34 \\
\hline Thinking & Systemic thinking & Strategic and systems conceptual thinking & 19 \\
\hline \multicolumn{3}{|c|}{ Grand Total } & 156 \\
\hline
\end{tabular}

\subsection{Process owner competencies: task related}

Task related competencies emerged from four task related categories:

(a) BPM (count $=79)$;

(b) customer focus (count $=10)$;

(c) process change facilitation (count $=9$ ); and

(d) process governance (count $=5$ ).

BPM competency requirements were observed to be a balance between understanding and practical application of BPM activities. Specific understandings identified were:

(i) process design and improvement methodologies, tools and techniques (count $=45$ ), 
(ii) process management principles (count $=8$ ),

(iii) BPM frameworks, standards, and implementation (count $=8$ ),

(iv) numerical and data analytical skills (count $=6$ ),

(v) technology architecture supporting business processes (count $=4$ )

(vi) process mapping standards (count $=3$ ),

(vii) implementation and monitoring of process metrics and measurements (count $=3$ ), and

(viii) work demand and staff capacity planning requirements (count $=2$ ).

Respondent IP4 encapsulated task related competencies as “... identify all the relevant processes... to monitor the process... too much capacity, do you have too little capacity... how does technology enable... based on people, process and technology. People and technology will support the process... legislation and compliance... need to understand it, they need training on it... to understand the importance of following the process, in alignment with our customer value proposition... to think out of the box... able to motivate... to persuade people down the right path."

\subsection{Process owner competencies: people}

People competencies are categorised as (a) interpersonal (count $=26$ ) and (b) organizational understanding (count $=8$ ). Interpersonal competencies emerging from the interviews included: (i) influence and negotiation with personal mastery (count $=10$ ); (ii) people management and motivation (count $=7$ ); (iii) communication (count $=4$ ); (iv) leadership and management (count $=3$ ); and (v) creative and innovative thinking (count $=2$ ).

According to respondent IP3 “... problem solving skills, and interpersonal skills... to be able to communicate effectively, because there is a reliance on other people to effect the process as intended. Innovation skills. Effective planning skills"

At the same time process owners must understand organizational context, culture and principles of organizational design. Respondent IP11 stated that "you need a good understanding of the business, business model, the whole value chain".

\subsection{Process owner competencies: thinking}

Systemic thinking (count $=19$ ) emerged as the third set of task related competencies and ranked second of all individual competencies below BPM methodologies and tools. Respondent IP2 noted "... able to apply systemic thinking... the ability to not just look at things in isolation." 


\subsection{Discussion of process owner competencies}

Although empirical research into process owner competencies is limited and little is known about what process owners should be doing, the findings can be contrasted with a South African study into competencies of business process analysts (Chakabuda, Seymour, \& Van Der Merwe, 2014). For process owners BPM competencies are emphasised more than interpersonal skills and organizational knowledge. Technical competencies are required for business process analysts and not for business process owners. However, for process owners governance is emphasised more strongly. In a South African study into competencies of enterprise resource planning (ERP) consultants, BPM competencies were also observed to be the highest ranked technical competencies. Nevertheless, overall interpersonal skills were ranked higher followed by business knowledge (Scholtz, Cilliers, \& Calitz, 2011). Further differences between process owners and ERP consultants included systemic thinking and the lower ranked competencies of focus on the customer, facilitating business process change, and process governance.

In terms of task competencies, meeting the needs of customers has been found to be at the core of business processes (Smart et al., 2009). In the conclusion of a quantitative study in the financial services industry the importance of BPM in driving customer satisfaction is emphasised (Kumar et al., 2008). Process changes also impact the design of organizations (Nesheim, 2011) which must be prepared for cultural change (Smart et al., 2009). Such change must be addressed from a process perspective and properly governed. Ongoing governance must also support a change management system in affecting process changes (Smart et al., 2009). A definitive link exists between customer focus, alignment and governance (de Bruin \& Rosemann, 2005).

In this study, some interviewees showed concern that process owners wield too much power in the organisation which could lead to interpersonal conflict. In prior studies, interpersonal skills have been found to be significant and although competence and trust in process owners were deemed to be high, communication skills were ranked moderately lower. Consequently, it was recommended that process owners communicate and engage in real dialogues that build relationships (Nesheim, 2011).

Systemic thinking is an important competency of process owners who need to be creative in process design (Nesheim, 2011). They must understand the process in its entirety including boundaries and inter-relationships (Smart et al., 2009). A holistic view combining strategy, operations, people, techniques and people with alignment to corporate objectives, governance and customer focus are important for adequate BPM (de Bruin \& Rosemann, 2005).

\section{$5 \quad$ PROCESS OWNER TASKS}

Three clusters of process owner tasks emerged from the research: planning (count $=196$ ); control (count $=68$ ); and governance (count $=15$ ) with significant overlap between individual concepts both inter-task and between tasks and competencies. This is in accordance with the view of competencies as knowledge, skills and attitudes required for performing tasks (Ravesteyn et al., 2008). The primary process owner tasks were observed to be metrics control and planning, customer experience planning 
and process change planning as shown in Table 3. Process change was highly ranked for control and governance while capacity planning also ranked highly.

\subsection{Process owner tasks: planning}

Nine categories of planning tasks were observed:
(a) process measurement (count $=45)$
(b) customer focus (count $=43$ );
(c) business process change (count $=34$ );
(d) governance (count $=24)$;
(e) capacity planning (count $=19)$;
(f) staff training (count $=15$ );
(g) technology (count $=7$ );
(h) strategic alignment (count $=6)$; and
(i) change management (count $=3$ ).

Process measurement planning activities included:

(i) identifying, designing and implementing process metrics and measurements (count $=26)$;

(ii) implementing process metrics reporting mechanisms (count $=8$ );

(iii) identifying and implementing staff process key performance indicators (count $=7$ );

(iv) conducting time and motion studies (count $=3$ ); and

(v) aligning staff remuneration with improvement agenda (count $=1$ ).

Respondent IP2 commented on “... ensuring that the line functions have appropriate measurements... and reinforcing that by metrics and incentives... Constantly testing what you have done with the market..."

Four customer focused planning tasks were identified:

(i) design customer-focused interaction mechanisms (count $=14$ );

(ii) design processes in line with customer expectations (count $=13$ );

(iii) identify customer process performance expectations (count $=11$ ); and

(iv) design customer entry-points and transactions (count $=5$ ).

Respondent IP3 stated that “... we want to improve customer experience... design now will identify at what points we push and pull feedback... how that alignment has come through ..." 
Table 3: Process owner tasks

\begin{tabular}{|c|c|c|c|}
\hline Category & Sub-category & Basic theme & Count \\
\hline \multirow{21}{*}{ Planning } & \multirow{5}{*}{$\begin{array}{l}\text { Process } \\
\text { Measurement }\end{array}$} & $\begin{array}{l}\text { Identify, design and implement balanced process metrics and measure- } \\
\text { ment }\end{array}$ & 26 \\
\hline & & Implement process metrics and measurement reporting mechanisms & 8 \\
\hline & & Identify and implement staff KPI's aligned to process & 7 \\
\hline & & Conduct time and motion studies and process activity standard times & 3 \\
\hline & & $\begin{array}{l}\text { Align staff remuneration and recognition in line with improvement } \\
\text { agenda }\end{array}$ & 1 \\
\hline & \multirow{4}{*}{$\begin{array}{l}\text { Customer } \\
\text { Experience }\end{array}$} & Process design with customer interaction trigger mechanisms & 14 \\
\hline & & Design process in line with customer expectations & 13 \\
\hline & & Identify customer process performance expectations & 11 \\
\hline & & Design customer entry points and define transaction types & 5 \\
\hline & \multirow{5}{*}{ Process Change } & $\begin{array}{l}\text { Identify incremental and re-engineering process enhancement opportun- } \\
\text { ities with staff involvement }\end{array}$ & 18 \\
\hline & & Design process with minimal process hand-off's & 10 \\
\hline & & Create and execute process improvement plans & 2 \\
\hline & & Identify process automation opportunities & 2 \\
\hline & & Pilot process design to ensure meeting performance objectives & 2 \\
\hline & Governance & $\begin{array}{l}\text { Design efficient process with governance \& internal control considera- } \\
\text { tions }\end{array}$ & 24 \\
\hline & Capacity & Conduct demand and capacity planning activities & 19 \\
\hline & \multirow{2}{*}{ Staff Training } & $\begin{array}{l}\text { Develop and conduct staff training initiatives in line with customer, } \\
\text { process, product and systems expectations }\end{array}$ & 9 \\
\hline & & $\begin{array}{l}\text { Develop skills matrix and staff capability requirements in line with pro- } \\
\text { cess design }\end{array}$ & 6 \\
\hline & Technology & Define technology enablers & 7 \\
\hline & Alignment & Align process objectives with organizational goals & 6 \\
\hline & $\begin{array}{l}\text { Change } \\
\text { Management }\end{array}$ & Engage impacted stakeholders on process changes & 3 \\
\hline \multicolumn{3}{|c|}{ Planning Total } & 196 \\
\hline \multirow{9}{*}{ Control } & \multirow{5}{*}{$\begin{array}{l}\text { Process } \\
\text { Measurement }\end{array}$} & Process performance monitoring & 31 \\
\hline & & $\begin{array}{l}\text { Report on process and staff performance with utilisation of visual man- } \\
\text { agement tools }\end{array}$ & 7 \\
\hline & & Obtain continuous customer satisfaction and expectation of process & 4 \\
\hline & & Active management of process exceptions & 3 \\
\hline & & Monitor of staff performance metrics & 3 \\
\hline & \multirow{3}{*}{ Process Change } & Identify process improvement opportunities on a continuous basis & 12 \\
\hline & & Focused process hand-off management and tracking & 3 \\
\hline & & Focus on Customer retention & 1 \\
\hline & Capacity & Demand and capacity planning and monitoring & 4 \\
\hline \multicolumn{3}{|l|}{ Control Total } & 16 \\
\hline \multirow{4}{*}{ Governance } & \multirow{2}{*}{ Process Change } & Process maintenance and continuous update & 9 \\
\hline & & Define and conform to process documentation standards & 1 \\
\hline & $\begin{array}{l}\text { Change } \\
\text { Management }\end{array}$ & Process communication and awareness & 3 \\
\hline & Staff Training & Utilise process documentation knowledge to facilitate staff training & 2 \\
\hline \multicolumn{3}{|c|}{ Governance Total } & 15 \\
\hline
\end{tabular}


Five specific business process change tasks were identified:

(i) identify incremental and re-engineering process enhancement opportunities (count $=18$ );

(ii) design processes with minimal process hand-offs (count $=10$ );

(iii) create and execute process improvement plans (count $=2$ );

(iv) identify process automation opportunities (count $=2$ ); and

(v) design pilot process to prove performance meeting abilities (count $=2$ ).

Respondent IP2 stated “... where we going to have incremental effort, where we going to have major re-engineering effort... Almost like a journey plan... Test what the customers are experiencing in the new process."

Ranked fourth of the planning categories but third as an individual task was governance in line with corporate policies and standards (count $=24$ ). Controlling and planning of metrics was ranked slightly higher than governance followed by capacity planning. Respondent IP3 stated that "standards and procedures... must be maintained and reviewed periodically to ensure they are aligned".

Capacity planning (count $=19$ ) was ranked fifth for planning tasks and fourth as an individual task. In support, respondent IP6 stated "... to measure the data on a daily basis, what's there, what the demand, what work was left over, how many people they've got."

Two aspects of staff training were identified: (i) development of organizational knowledge (count $=9$ ); and development of business process skills (count $=6$ ) which speaks more to education from an academic perspective. Respondent IP4 stated "... they need to understand it, they need training on it, they need to understand what the repercussions or impacts are on the process, they need to understand the importance of following the process."

The seventh task was identified as the determination of technology requirements in line with process objectives (count $=7$ ). For example, IP4 stated “... how does technology enable... technology will support the process."

Strategic alignment of business processes with business objectives (count $=6$ ) emerged as the eighth planning task of business process owners. In support, IP4 stated "a systematic approach to align an organisation's process."

The ninth and last planning task of process owners was identified as change management (count =3). Participant IP5 stated "using change management process... with diplomacy rather than forced fit."

\subsection{Process owner tasks: controlling}

Controlling emerged as the second process owner task category and includes (a) controlling process metrics (count $=48$ ), (b) business process change (count $=16$ ) and (c) capacity planning (count $=$ 4).

Process metrics monitoring emerged as the primary controlling task. Five activities were identified: (i) monitor process performance (count $=31$ ); (ii) provide process performance reports (count $=$ 
7); (iii) monitor customer satisfaction and process expectations (count $=4$ ); (iv) monitor process performance metrics (count $=3$ ); and $(\mathrm{v})$ manage process performance exceptions (count $=3$ ). Participant IP6 stated: “... monitor them, understand if there are exceptions, what the exceptions are... and take necessary action. Continuous monitoring, understanding and questioning."

Business process change controlling tasks were found to comprise three activities: (i) identify process improvement opportunities (count $=12$ ); (ii) manage process hand-offs (count $=3$ ); (iii) monitor customer retention (count $=1$ ). For example, participant IP7 stated "the first objective would be to just reduce hand-offs dramatically...then do hand-offs... in a controlled and result based mind-set."

Monitor capacity planning (count $=4$ ) was ranked third of the controlling tasks for process owners. Respondent IP4 stated "also look at capacity... because that impacts our processing time."

\subsection{Process owner tasks: governance}

The final task category was governance (count $=15$ ) comprising (a) governing process change (count $=10$ ), (b) process exception management (count $=3$ ) and (c) documentation for staff process training (count $=2$ ).

Two tasks emerged for governing process change: (i) review and maintain processes (count $=$ 9); and (ii) conform to process documentation standards (count $=1$ ). Respondent IP3 stated that "the process needs to be documented... standards and procedures and those must be maintained and reviewed periodically."

\subsection{Discussion of process owner tasks}

Process owners track business process performance through metrics which are used as guides for improvement (Hammer \& Stanton, 1999). Consequently, process measurement is essential for performance management and integral to BPM (Armistead et al., 1999). The aim of measurement is consistent and optimised process performance from economic and customer requirements perspectives (Smart et al., 2009). However, these measurements must be balanced and aligned to organizational goals with the aim of improving processes (van der Aalst et al., 2016). This finding empirically confirms the close cooperation between appointing process owners and process performance measurement which should be implemented in tandem (Kohlbacher \& Gruenwald, 2011). However poor process design may cause a performance ceiling whereby the effectiveness of processes is limited. This finding underlines the importance of appointing process owners (Kohlbacher \& Gruenwald, 2011) and the need for process improvement (Smart et al., 2009; Hammer, 2002). In support of these findings, a similar study observed the most important tasks of process owners to be monitoring process improvement; problem solving; and initiating process improvement (Reijers \& Peeters, 2010).

While customer satisfaction is important (de Bruin \& Rosemann, 2005) it has been shown to be a low success factor in BPM (de Bruin, 2007). Focus on measurement of customer requirements (Smart et al., 2009) rather than customer satisfaction or experience may be the reason for this finding. This 
is exemplified in the view that organizational design and internal issues are key to BPM success (Nesheim, 2011). Consequently, customer satisfaction should be part of the process measurement mix driving process change and improvement. Process improvement meanwhile is observed as (a) improvement of business processes (Smart et al., 2009; Hammer, 2002), and (b) as improvement in the process approach evolving from modelling to process improvement (de Bruin, 2007). An issue brought to light in this study and recognised as being of importance is the management of handoff boundaries between processes to ensure sustainable organizational performance and meeting customer and stakeholder expectations (Armistead et al., 1999).

Process change may be accomplished either incrementally or through radical changes to business processes (Armistead et al., 1999). Radical change or process re-engineering can be highly disruptive and consequently, process owners must constantly be aware of process improvement opportunities (Reijers \& Peeters, 2010).

A further low success factor of BPM is governance (de Bruin, 2007) which is defined as: process management decision making; process roles and responsibilities; process metrics and performance linkages; process-related standards; and process compliance (Doebeli et al., 2011). Governance is crucial in BPM which aims at standardisation of processes from the ideology of "one-best-way" (Nesheim, 2011). However, process owners have been observed to become obsessed with compliance which may lead to interpersonal conflict. A further concern is the practice of governance being limited to maintaining documentation (Reijers \& Peeters, 2010).

A source of dispute may arise from the vital task of staff capacity planning when trying to provide a balance between optimal process performance and optimal organizational performance. Process owners need to instill trust and prove efficiency in distributing resources. Although some authors focus on incremental change (Nesheim, 2011) others focus on resource allocation during process improvement projects to ensure process compliance (Larsen \& Klischewski, 2004; Reijers \& Peeters, 2010). Linked to staff allocation is staff training. Process owners must ensure that staff allocated to the processes are suitably trained and understand the process they perform (Hammer, 2002). Such training must address staff competence from a strategic perspective at both the individual and collective levels (Nesheim, 2011).

Technology is vital to BPM (Antonucci \& Goeke, 2011) which together with strategic alignment, governance, methods, people, and culture is the core of BPM (Rosemann \& vom Brocke, 2015). BPM systems (BPMS) can be used to manage, control and support operational processes and can connect with legacy systems, cloud networks and mobile devices (van der Aalst et al., 2016). However, technology has been observed as a low ranked competence amongst process oriented practitioners (Scholtz et al., 2011).

A further low success factor of BPM is strategic alignment (de Bruin, 2007). Nonetheless, it is considered vital to a comprehensive BPM approach (de Bruin \& Rosemann, 2005) and the first of the six core elements of BPM (Rosemann \& vom Brocke, 2015).

Although change management was not ranked high in this study it is essential in supporting process governance and maintaining an ongoing representation of processes (Smart et al., 2009). It may however be tempered by lack of readiness of the organisation to accept cultural change (Smart et al., 2009) which will impede process improvement (Niehaves et al., 2014). Organizational 
resistance is known to provide major roadblocks to the successful execution of BPM initiatives (van der Aalst et al., 2016).

\section{SUMMARY OF TASKS AND COMPETENCIES}

While process owner competencies and tasks are poorly defined in the literature (Nesheim, 2011) the findings from this study show that practitioners' understandings are in accordance with the BPM requirements from the early days of the field. Armistead (1996) provided ten principles of managing business processes: (i) designate a process champion; (ii) know the process (iii) understand the linkages; (iv) work on the trade-offs; (v) teach others about the process; (vi) train within the process; (vii) measure the process; (viii) manage careers; (ix) build specialist expertise; and (x) improve the process. Three groups of tasks have been suggested: designing processes, day-to-day process management; and nurturing process related learning (Paim et al., 2008). Over time technology has become more relevant while interpersonal skills have become vital (Scholtz et al., 2011). In addition, a need for a stronger focus on a holistic view and alignment of strategy, operations, and people to corporate objectives, governance and customer focus has emerged (de Bruin \& Rosemann, 2005).

The tasks described are shown to be relevant to practitioners' belief of process owner competencies and tasks. Whereas the process owner should be a permanent position (Hammer \& Stanton, 1999) in the case organizations process management was found to be performed intermittently and the appointment of process owners was observed to be limited: IP1 stated that: "The one principle we have agreed on is that processes can't be owned by a process custodian or process engineer, it must be owned by the people who do the work every day. The business." This imposes limitations to the study and the findings which show aspirations of business for a process management solution that may be more theoretical than based on experience.

A further limitation is that the study involved only financial services organizations within a geographic region and hence cognizance must be taken of differences between BPM in the manufacturing sector and the services sector. Business process focus has been found to be significantly lower in service sector organizations than in manufacturing sector organizations (Goeke \& Antonucci, 2013). This resonates with the low level of process focus observed in the study as shown in the following excerpts from the interviews. Participant IP6 stated "... but the processes... are still working in silos." Participant IP3 stated "... the processes enable us to manage work, as it suits us but they have not been design[ed] with the customer in mind."

\section{FRAMEWORK CONCEPTS}

In this section we present thematic analysis of the most recent BPTrends practitioner survey and contrast this analysis with the process owner competencies and tasks from the primary interview data analysis. The analysis reveals similarities that provide a deeper understanding of the process owner findings. The resultant framework concepts linked to the primary data analysis is in Table 4 and is discussed in this section. We use the term respondent to refer to the BPTtrends survey participant 
responses. Note that in most cases the BPTrends respondents are commenting on their organizations and not in an individual capacity. Relationships between the concepts are then presented as a conceptual framework in the next section and contrasted with literature.

Table 4: Process Owner (PO) Framework Concepts mapping

\begin{tabular}{|c|c|c|c|c|}
\hline Framework concepts & PO Type & PO Categories & PO Sub-category & Count \\
\hline \multirow{2}{*}{ Governance } & Task & Planning & Governance & 24 \\
\hline & Competency & Task & Process Governance & 5 \\
\hline Systemic Thinking & Competency & Thinking & Systemic Thinking & 19 \\
\hline \multirow{2}{*}{$\begin{array}{l}\text { Metrics \& performance } \\
\text { monitoring }\end{array}$} & Task & Planning, Control & Process Measurement & 93 \\
\hline & Competency & Task & BPM: process metrics and measurements & 3 \\
\hline Process Improvement & Competency & Task & BPM: process design and improvement & 45 \\
\hline \multirow{3}{*}{ Process Management } & \multirow{2}{*}{ Competency } & Task & BPM: process management & 16 \\
\hline & & People & Interpersonal & 26 \\
\hline & Task & Planning, Control & Capacity & 23 \\
\hline \multirow{3}{*}{ Process Change } & \multirow[t]{2}{*}{ Task } & $\begin{array}{l}\text { Planning, Control, } \\
\text { Governance }\end{array}$ & Process Change & 60 \\
\hline & & Planning, Governance & Change Management & 6 \\
\hline & Competency & Task & Process Change Facilitation & 9 \\
\hline BPM Methodology & Competency & Task & BPM: methodology/framework & 8 \\
\hline \multicolumn{5}{|l|}{ Process Architecture } \\
\hline $\begin{array}{l}\text { Business Process Model- } \\
\text { ling }\end{array}$ & Competency & Task & BPM: process mapping & 3 \\
\hline \multirow{2}{*}{ BPM Automation } & Task & Planning & Technology & 7 \\
\hline & Competency & Task & BPM: technology architecture & 4 \\
\hline $\begin{array}{l}\text { Training and document- } \\
\text { ation }\end{array}$ & Task & Planning, Governance & Staff Training & 17 \\
\hline \multirow{2}{*}{ Customer Focus } & Task & Planning & Customer Experience & 43 \\
\hline & Competency & Task & Customer Focus & 10 \\
\hline Organisational Goals & Competency & People & Organisation Understanding & 8 \\
\hline Strategic Alignment & Task & Planning & Alignment & 6 \\
\hline
\end{tabular}

\subsection{Governance and systemic thinking}

Governance permeated the primary data, from competency to being observed as one leg of process owner tasks. This included planning governance tasks which comprise: reviewing and maintaining business processes; conforming to documentation standards; ensuring staff are trained; and affecting change management. For the BPTrends survey, limited reference to governance was described. Nevertheless, it was observed to be a current item of focus as a business tool linked to enterprise-wide process management for $22 \%$ of respondents.

Thinking was referred to in both data sets. While creative and innovative thinking in dealing with people was observed as a requisite competency, a strong need for systemic process thinking was identified. This resonates with $10 \%$ of BPTrends respondents reporting on the responsibility of process managers in ensuring that all managers think in terms of process. 


\subsection{Metrics and performance monitoring}

Implementation and monitoring of process metrics and measurement was ranked 7 out of 9 BPM task-related competencies of process owners. Although process measurement has a low competency requirement it was observed to be significant for planning and controlling tasks. Sub-tasks for process measurement planning comprise identifying, designing and implementing process metrics and measurements, implementing process metrics reporting mechanisms, identifying and implementing staff process key performance indicators, conducting time and motion studies, and aligning staff remuneration with improvement agenda. Controlling tasks entail monitoring process performance, providing process performance reports, monitoring customer satisfaction and process expectations, monitoring process performance metrics, and managing process performance exceptions. Process performance monitoring and measurement was also identified as an important task of process owners. These tasks include: monitoring process performance, identifying process enhancement opportunities; identifying customer process performance expectations; identifying and implementing staff process key performance indicators; providing process performance reports; monitoring process performance metrics; managing process performance exceptions; and designing pilot tests to prove performance meeting abilities.

Low usage of metrics and performance monitoring is reflected in the BPTrends finding with only $27 \%$ of respondents frequently having comprehensively defined metric and $73 \%$ of respondents occasionally if ever making use of performance data. Metrics and performance monitoring is nevertheless deemed important with 19\% of respondents currently implementing a performance measurement system and $46 \%$ intending using consultants for strategizing and planning the development of enterprise performance measurement systems and 18\% for Balanced Scorecards. While 19\% of respondents report the use of a process monitoring/BI tool only $5 \%$ regard such a tool as valuable. Nevertheless, $18 \%$ of respondents indicated anticipated spend on development of an enterprise process performance measurement systems.

\subsection{Process improvement, process management and process change}

Process improvement and process management are the leading competencies required by business process owners. From the BPTrends survey, process improvement is an important driver for 33\% of the respondents. The level of importance of this driver is further noted in that $20 \%$ have Six Sigma improvement initiatives underway while future initiatives for training in process improvement methodology is $24 \%$. The low use of improvement methodologies and importance of training supports the finding that $41 \%$ of respondents report their dominant process methodology to be incremental focused on process improvement.

Closely related to process improvement is process change as one of the leading tasks for process owners. Process owners require change facilitation competencies in order to perform process change tasks including; managing the process changes; identifying process enhancement opportunities; identifying process automation opportunities; designing efficient processes; designing pilot tests; creating and executing process improvement plans; monitoring, reviewing and maintaining the process changes; monitoring the impact on customer retention; and ensuring that the processes 
conform to the process documentation and standards.

The BPTrends survey found that the second highest ranked process methodology focuses on process change from a top-down approach (25\%) in contrast to the highest ranked methodology that focuses on incremental improvement. Process change was observed to be significant in current business process initiatives with $26 \%$ of the respondent's organizations coordinating enterprise process change. Assistance with culture and process change is provided by outside consultants for $49 \%$ of the respondents. The consequence of this approach has resulted in multiple change efforts all competing for attention. This is challenging the widespread acceptance of process efforts second only to the lack of process focus by senior management.

\subsection{BPM methodology and process architecture}

BPM methodology standards and implementation was determined as the third most significant process owner BPM competency. BPTrends reports 21\% of respondents looking to consultants for assistance with BPM methods. Less than one third (30\%) report having an enterprise-wide standard methodology. Of the remaining 70\%, 34\% report considering standardizing their BPM methodology.

The primary data analysis showed little involvement of process owners with process architecture and therefore was not identified as a task or competency. The BPTrends survey, however, indicates the potential importance of architecture with $43 \%$ of respondents currently developing an enterprise process architecture and $42 \%$ of respondents reporting on the use of outside consultants for helping with enterprise process architecture development. Likewise, 16\% of respondents are currently training in process strategy, architecture, or performance which is anticipated to increase to $23 \%$. Consequently, process architecture was added as a framework concepts even though it was mostly absent from the primary data analysis.

\subsection{Business process methodology and BPM automation}

The process owner findings reported a weak need for process mapping skills indicating that modeling was being undertaken by other BPM experts. The BPTrends survey had ample reference to modeling. This is seen in the maturity status summary which shows that value chain modeling was the most advanced of the maturity measures with $49 \%$ of respondents reporting frequent modeling of value chains. Furthermore, high levels of process standards adoption by organizations, such as BPM notation (BPMN) (64\% of respondents) implies active use of modeling in organizations.

The most important process owner competencies were observed to be process design and improvement methodologies, tools, and techniques. This reflects an importance of technology tools. At the same time the need for competence in business process supporting technology architecture was ranked low. The BPTrends survey reflects a positive but low importance of business process automation with $62 \%$ of respondents reporting occasional to never using business process automation and $25 \%$ of respondents automating only some processes. Assistance from outside consultants is used by $75 \%$ of respondents while $9 \%$ use consultants specifically for ERP support of BPM. However, BPM methodology determined by software was ranked third by respondents (19\%). Automation 
of processes by means of BPMS is used by $28 \%$ of the respondents and $19 \%$ reported the use of a Business Intelligence/Process Monitoring tool to feed an executive dashboard. Tools for managing rule-based processes was also reported by $7 \%$ of respondents. Use of BPMS was observed to be the second most valuable software tool by the respondents (19\%) after business process modeling tools. The importance of automation software was revealed in the $21 \%$ of respondents with current BPMS initiatives and the respondents anticipating automation spend in the 12 months following the survey (19\% on BPMS, $8 \%$ on rule-based tools).

\subsection{Training and documentation}

Training was observed to be part of the planning tasks of process owners. Process owners must ensure that process staff are trained to have both organizational knowledge and process knowledge. To assist in staff training, processes, standards and procedures should be documented, maintained, and reviewed regularly. The relatively low priority of training identified in the process owner tasks (ranked 6 out of 9 tasks) is reflected in the BPTrends survey. Only 10\% of respondents train all their managers to think as process managers. Nevertheless, training was observed to be important in the BPTrends survey as observed in the use of consultants for training combined with the volume of training done currently and planned for the immediate future. Consultants are used in $43 \%$ of the organizations for process manager training and $24 \%$ for process analysis and design training. The most popular form of training identified was BPM conferences (23\%). This was followed by BPM systems training (25\%), process redesign and improvement methodology (24\%), process strategy, architecture, or performance (23\%), and process analysis and design (18\%).

Documentation appears to be taken for granted for process owners both in competencies and tasks with only a single reference to the need to conform to process documentation standards for business process change. The existence of process documentation is implied in the higher ranked task of reviewing and maintaining processes. Similarly, the BPTrends survey identified implied documentation in the section on maturity status which found that while $50 \%$ of respondents have only occasionally updated process documentation, $46 \%$ of respondents had regular to always updated process documentation. Likewise, $47 \%$ reported that defined and documented skill requirements were only occasionally updated while $45 \%$ have frequently to always updated skill requirements.

\subsection{Customer focus and organizational goals}

Customer focus was identified as the second most important competency for process owners, after BPM competencies. Likewise, customer focus ranked highly in process owner tasks requiring process owners to: design customer-focused interaction mechanisms; identify customer process performance expectations; design processes in line with customer expectations; design customer-entry points; and monitor customer satisfaction, process expectations, and retention. The importance of customer focus is highlighted in the BPTrends survey with customer satisfaction ranked as the second most important driver of BPM (46\% of respondents) closely following cost reduction (53\%). In this context customer focus is seen as an organizational goal. 
The process owner study did not explicitly refer to organizational goals other than customer focus, strategic alignment and metrics. However, organisation understanding was a competency required of process owners which included understanding organizational context, the value chain, and organisation culture.

\subsection{Strategic alignment}

The process owner study indicated the need for strategic alignment tasks. In the BPTrends survey alignment between business and processes is seen to be fundamental. While most of the findings are arguably strategic in nature, the survey identified explicit alignment elements. For example, the top three drivers of BPM (cost reduction-53\%, customer satisfaction improvement-46\%, product improvement-33\%) are readily rephrased as organizational strategies. Likewise, organization's understanding of BPM as a focus on core processes from a control perspective (33\%) may be classified as strategic. Furthermore 24\% of respondents classified their organization's current interest in BPM as strategic commitment.

The top-down process methodology dominant amongst $25 \%$ of respondents furthermore indicates the commitment to strategic alignment. From a maturity status perspective, strategic alignment was found to be one of the more progressive factors with $43 \%$ of respondents reporting standardisation of processes across functions frequently to always. However, this is not reflected in the manager responsibilities with $14 \%$ of respondents indicating manager responsibilities extending across value chains. Only 19\% reported current focus on redesigning enterprise-wide processes supporting a lack of executive level involvement. Additionally, while 15\% reported having a BPM group at executive level, almost a third of respondents (32\%) reported having no BPM group. The low level of direct executive involvement or lack of a BPM group is observable in the high use of consultants for strategy and planning. The greatest use of consultants (52\%) is reported as assisting with defining the relationship between strategy and process. Exacerbating the inability to align strategy and business is the lack of a standard enterprise-wide BPM methodology.

Insight into the relatively low levels of executive support is provided by the BPTrends findings on challenges to widespread acceptance of process efforts. The most significant challenge is the lack of senior management interest or focus elsewhere (58\%). Some specific reasons were supplied with $24 \%$ of respondents reporting that management do not want to make investment while $30 \%$ demand untenable return on investment estimates. A further issue for $25 \%$ of respondents, for which lack of executive support may be both a cause and result, was management being cautious due to earlier process project failures.

\section{DISCUSSION OF FRAMEWORK}

The common and interlinking themes emanating from the comparison of the process owner study and BPTrends survey were used to define the process owner competency framework depicted in Figure 1 and discussed below. The core of BPM is shown in the inner highlighted block. BPM interacts 
with the organizational goals based on and aligned to the organization's strategy and overarched by governance. All of which is underpinned by documentation and training.

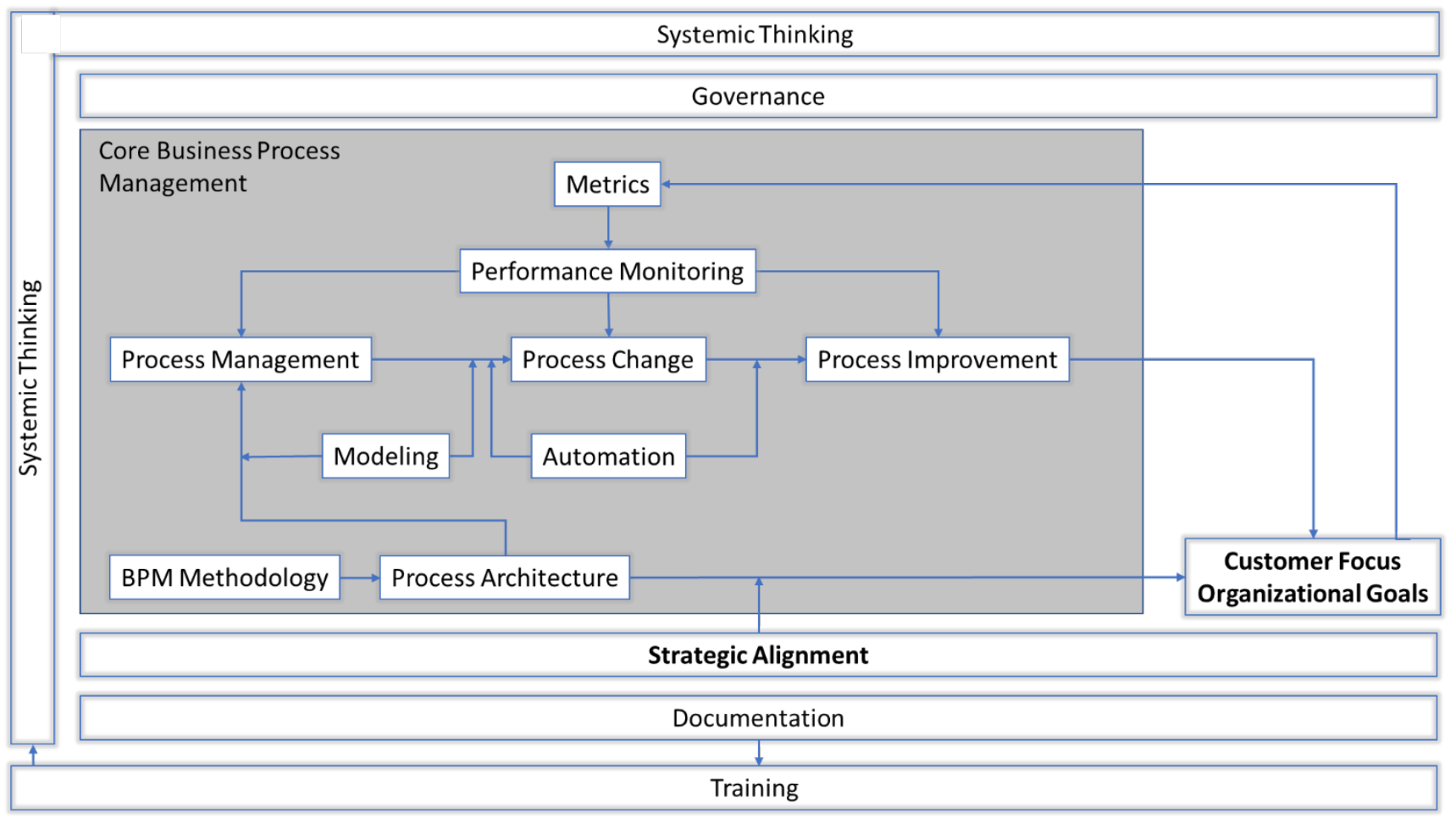

Figure 1: Business Process Owner Competency Framework

In the process owner study the primary driver was found to be customer satisfaction. This was also a key driver of BPM observed in the BPTrends survey, followed by cost saving and productivity improvement. However, satisfaction is a nebulous quality and consequently Hammer (2015) tends to refer to both customer value and fulfilling customer expectations. This is highlighted in the iron triangle of customer, result, and processes whereby higher organizational performance is afforded through the output (result) of processes that directly influences customers (Hammer, 2015). Hence this combination is considered the primary driver of organizational goals. More broadly, a better process is defined simply as one that better meets an organization's strategic objectives (van der Aalst et al., 2016).

Organizational goals must originate with the top management team or upper echelons (Hambrick, 2005). To be effective all organizational actions must be synchronised with these goals. This is a function of strategic alignment which must trigger all business process functions. Consequently, strategic alignment is depicted as underlying all the BPM constructs. Strategic alignment is regarded as a moderator between organizational goals and process architecture. The customary view of strategic alignment describes it as a "tight linkage" (Rosemann \& vom Brocke, 2015, p. 110) between BPM and organizational goals. Strategic alignment consists of process improvement planning; 
strategy and process capability linkage; enterprise process architecture, process measures; and process customers and stakeholders (Rosemann \& vom Brocke, 2015). Limited involvement of executives results in low level of access to planning and particularly long-term planning for BPM. Tasks that do not have executive attention cannot be infused with the initiatives of executives and, consequently, may either not be successful or perform contrary to organisation strategies. This is highlighted by Rosemann and vom Brocke (2015, p. 114) who point out that strategic alignment capabilities must include stakeholders as high-placed individuals who can have a "significant impact" on an organization's BPM even though the BPM strategy remains constant.

The BPTrends survey notes the persistent relatively equal division of process needs between strategy, enterprise process architecture and enterprise measurement (Harmon \& Wolf, 2016). On the other hand, Rosemann and vom Brocke (2015) link capabilities of strategy, enterprise process architecture, and process measurement together with process improvement, business processes, and customers and stakeholders under the primary BPM core element of strategic alignment.

To be effective BPM must be based on a defined, documented, and structured process architecture (Hammer, 2015). This in turn requires a BPM framework to outline the different elements of BPM and to facilitate prioritizing elements of BPM (Rosemann \& vom Brocke, 2015). Lack of a process architecture may lead to uncoordinated process initiative (Hammer, 2015) and competing demands for resources causing difficulties prioritizing conflicting process change initiatives as observed in the current study. Process architecture, whether formal or ad-hoc, defines the management of processes. Effective execution of a process requires good design (Hammer, 2015) for which enterprise process architecture provides a blueprint. The aim of enterprise process architecture is to provide a high-level abstract of the "actual hierarchy of value-driven and enabling business processes" (Rosemann \& vom Brocke, 2015, p. 113).

One of the elements of designing processes is graphically modeling the process. Modeling is itself an ongoing task since processes need to be managed on an on-going basis (Hammer, 2015). An important component of process management is process monitoring which can translate directly into improved organizational performance and faster response to change (Hammer, 2015). This is accomplished through continual monitoring of processes and early reaction to problems rather than non-process oriented organizational systems that react to after-the-fact financial performance. Likewise, process owners must constantly remain aware of opportunities to improve existing processes.

Continual monitoring requires both documentation and metrics against which to measure performance. Metrics are supplied by the organizational goals and must be aligned to the organization's strategies. Deviations from metrics should be addressed as soon as they are identified. Execution faults must be investigated and addressed as soon as possible through training, resource allocation, fixing of faulty equipment, etc. (Hammer, 2015). Design faults, recognisable through the process producing persistently poor performance, may require a process change. Graphical modeling assists in understanding the current process (As-Is) and the desired process (To-Be). One form of change is to automate processes and modify the automation to produce improvements. Process change, however, does not guarantee process improvement and consequently process changes require ongoing management and monitoring. Process managing and monitoring continue into the process improvement 
space. Process management, change, and improvement all feed into satisfying organizational targets which feed back into process metric determination.

Underpinning the entire BPM system is documentation beginning with the creation of a formal process (Hammer, 2015). This is depicted by means of a block stretching across the model indicating inputs to documentation throughout the management process. According to the BPTrends study (Harmon \& Wolf, 2016) the need for ongoing effort of accurately describing processes and their performance is undervalued by executives with resultant resistance to invest in process architecture. Low understanding and valuation of the business processes by executives hinders the business process initiatives. This was noticeable in the challenges to acceptance of process efforts.

Training is depicted as stretching across the entire scope of the model including systemic thinking. Processes and staff skill requirements must be documented to provide input for training which would at best be hit and miss without well-defined documentation (Hammer, 2015). Requirements for process and staff training can be differentiated between two methods of addressing performance shortfalls; faulty design; and faulty execution (Hammer, 2015). Design faults are persistent and easy to identify as sub-standard performance although they are difficult to remedy. On the other hand, execution faults are hard to identify as they could result from several inadequacies. However, once identified faulty execution is easily remedied for which operational training is one form of solution. In turn documentation provides input for such training.

Intricate to the entire system and connecting it to the environment is the ability to think systemically which can be enhanced through training.

Definition and documentation of process roles and responsibilities and enterprise-wide process management standards is a central aspect of governance (Rosemann \& vom Brocke, 2015). The primary objective of governance is to ensure consistent execution of processes which enact documented standards aligned with strategy. To ensure strategic alignment, processes must be constantly reviewed and measured. This, together with collecting the required metrics, is part of the task of governance (Rosemann \& vom Brocke, 2015). Meanwhile, effective process change is dependent on governance (Smart et al., 2009) which is intricately linked to alignment and customer focus (de Bruin \& Rosemann, 2005). For this reason, governance is depicted as an overarching concept in Figure 1.

An alternative explanation of limited process orientation is the view that traditional organizations are "unfriendly" to processes (Hammer, 2015, p. 8). Without a realignment of the organisation to support a process-oriented structure, BPM efforts will not succeed. Hammer (2015) posits five enablers of process: process design; process metrics; process performers; process infrastructure; and a process owner. Coordinated process design based on enterprise process architecture, implemented through process management and maintained through process change prevents uncoordinated individual process activity and "organizational chaos" (Hammer, 2015, p. 8). Process metrics derived from "customer needs and enterprise goals" (Hammer, 2015, p. 9) are visibly in evidence. Underlying process execution, and noticeable in the requirements for training, is the notion of specialised skills required by process performers. Likewise, organizational support in the form of process infrastructure is required for operation, automation and staffing of enterprise-wide processes. Finally, process owners are fundamental to process orientation and central to this study. 


\section{CONCLUSION}

This study set out to explore and describe the competencies and tasks required by process owners and to define a framework to assist practitioners in supplying critically needed process owner skills. Such a framework is necessary to address the lack of such models. Effective BPM requires a number of elements not least of which are process owners. This framework was formulated through analyzing interviews performed at three financial services organizations in South Africa and through analyzing the 2015 global BPTrends survey (Harmon \& Wolf, 2016). The framework was then validated against current BPM literature (Hammer, 2015; Rosemann \& vom Brocke, 2015).

Limitations identified in each of the studies individually were reduced through cross-referencing each other and to other literature. Limitations, however, still exist. Generally, the study is limited by the low number of actual process owners or process managers positions established in organisations. While BPM, BP analysts and BPM groups are more established, the reluctance to appoint process owners and the business case for their appointment needs more research.

In this framework process owner competencies are seen to range from core BPM to strategic alignment with organizational goals, and overarching competencies of documentation, training, governance, and systemic thinking. Core BPM hinges on a process architecture for process management, which is changed and improved through ongoing performance monitoring of metrics. The metrics are supplied through the organizational goals linked to strategic alignment. Assisting in core BPM are BPM frameworks, process modeling and process automation. Although all the competencies are necessary for effective process orientation, the underlying studies revealed limited use of many aspects. Lack of process architecture and limited upper echelon involvement limit process design and execution to individuals or departments. This restricted use hinders enterprise-wide benefits and causes top management to be wary of business process initiatives.

The first step in remedying this situation is education. This appears to be identified amongst the respondents as an array of BPM training was observed. An interesting observation was the expectation of increased attendance at business process conferences. Further research is indicated as this raises several questions, such as are current training offerings failing to educate sufficiently? A further opportunity for research is in differentiating between process redesign, process improvement and process execution. Inherent in the BPM core is the combination of all three, but separating their competencies is more challenging.

\section{References}

Antonucci, Y. L. \& Goeke, R. J. (2011). Identification of appropriate responsibilities and positions for business process management success: Seeking a valid and reliable framework. Business Process Management Journal, 17(1), 127-146. https://doi.org/10.1108/14637151111105616

Armistead, C. (1996). Principles of business process management. Managing Service Quality: An International Journal, 6(6), 48-52. https://doi.org/10.1108/09604529610149239 
Armistead, C., Pritchard, J.-P., \& Machin, S. (1999). Strategic business process management for organisational effectiveness. Long Range Planning, 32(1), 96-106. https://doi.org/10.1016/ S0024-6301(98)00130-7

Bhattacherjee, A. (2012). Social science research: Principles, methods, and practices. University of South Florida. Retrieved from http://scholarcommons.usf.edu/oa_textbooks/3/

Braun, V. \& Clarke, V. (2006). Using thematic analysis in psychology. Qualitative Research in Psychology, 3(2), 77-101. https://doi.org/10.1191/1478088706qp063oa

Chakabuda, T. C., Seymour, L. F., \& Van Der Merwe, F. I. (2014). Uncovering the competency gap of students employed in business process analyst roles-An employer perspective. In IST-Africa Conference Proceedings, 2014 (pp. 1-9). IEEE. https://doi.org/10.1109/ISTAFRICA.2014. 6880599

de Bruin, T. (2007). Insights into the evolution of BPM in organisations.

de Bruin, T. \& Rosemann, M. (2005). Towards a business process management maturity model.

Doebeli, G., Fisher, R., Gapp, R., \& Sanzogni, L. (2011). Using bpm governance to align systems and practice. Business Process Management Journal, 17(2), 184-202. https://doi.org/10.1108/ 14637151111122310

Dumas, M., La Rosa, M., Mendling, J., Reijers, H. A., et al. (2013). Fundamentals of business process management. Springer. https://doi.org/10.1007/978-3-642-33143-5

Goeke, R. J. \& Antonucci, Y. L. (2013). Differences in business process management leadership and deployment: Is there a connection to industry affiliation? Information Resources Management Journal (IRMJ), 26(2), 43-63. https://doi.org/10.4018/irmj.2013040103

Hambrick, D. C. (2005). Upper echelons theory: Origins, twists and turns, and lessons learned. Great minds in management: The process of theory development, 109-127.

Hammer, M. (2002). Process management and the future of Six Sigma. MIT Sloan management review, 43(2), 26. https://doi.org/10.1109/emr.2002.1167284

Hammer, M. (2015). What is business process management? In Handbook on business process management 1 (pp. 3-16). Springer. https://doi.org/10.1007/978-3-642-45100-3_1

Hammer, M. \& Stanton, S. (1999). How process enterprises really work. Harvard Business Review, 77, 108-120.

Harmon, P. \& Wolf, C. (2016). The state of business process management. Business process trends.

Kohlbacher, M. \& Gruenwald, S. (2011). Process ownership, process performance measurement and firm performance. International Journal of Productivity and Performance Management, 60(7), 709-720. https://doi.org/10.1108/17410401111167799

Kumar, V., Smart, P., Maddern, H., \& Maull, R. (2008). Alternative perspectives on service quality and customer satisfaction: The role of BPM. International Journal of Service Industry Management, 19(2), 176-187. https://doi.org/10.1108/09564230810869720

Larsen, M. H. \& Klischewski, R. (2004). Process ownership challenges in IT-enabled transformation of interorganizational business processes. In System Sciences, 2004. Proceedings of the 37th Annual Hawaii International Conference on (11-pp). IEEE. https://doi.org/10.1109/hicss. 2004.1265612 
Nesheim, T. (2011). Balancing process ownership and line management in a matrix-like organization. Knowledge and Process Management, 18(2), 109-119. https://doi.org/10.1002/kpm.377

Niehaves, B., Poeppelbuss, J., Plattfaut, R., \& Becker, J. (2014). BPM capability development-A matter of contingencies. Business Process Management Journal, 20(1), 90-106. https://doi. org/10.1108/BPMJ-07-2012-0068

Paim, R., Mansur Caulliraux, H., \& Cardoso, R. (2008). Process management tasks: A conceptual and practical view. Business Process Management Journal, 14(5), 694-723. https://doi.org/ 10.1108/14637150810903066

Ravesteyn, P., Batenburg, R., \& de Waal, B. (2008). In search of competencies needed in BPM projects. Communications of the IIMA, 8(2), 23.

Recker, J. \& Mendling, J. (2016). The state of the art of business process management research as published in the BPM conference. Business \& Information Systems Engineering, 58(1), 55-72. https://doi.org/10.1007/s12599-015-0411-3

Reijers, H. A. \& Peeters, R. L. (2010). Process owners in the wild: Findings from a multi-method descriptive study. In 1st International Workshop on Empirical Research in Process-Oriented Information Systems (ER-POIS 2010) (pp. 1-12).

Rosemann, M. \& vom Brocke, J. (2015). The six core elements of business process management. In Handbook on business process management 1 (pp. 105-122). Springer. https://doi.org/10. 1007/978-3-642-45100-3_5

Rudman, A., Garbutt, M., \& Seymour, L. (2016). Towards a framework of process owner competencies and tasks. In Proceedings of the 2016 Annual Research Conference of the South African Institute of Computer Scientists and Information Technologists (SAICSIT). ACM. https://doi.org/10. $1145 / 2987491.2987522$

Scholtz, B., Cilliers, C., \& Calitz, A. (2011). Critical competencies for South African ERP consultants. In Proceedings of the International Business Conference (IBC) (pp. 70-93).

Smart, P., Maddern, H., \& Maull, R. S. (2009). Understanding business process management: Implications for theory and practice. British Journal of Management, 20(4), 491-507. https: //doi.org/10.1111/j.1467-8551.2008.00594.x

Thomas, D. R. (2006). A general inductive approach for analyzing qualitative evaluation data. American Journal of Evaluation, 27(2), 237-246. https://doi.org/10.1177/1098214005283748

van der Aalst, W., la Rosa, M., \& Santoro, F. (2016). Business process management: Don't forget to improve the process! Business and Information Systems Engineering, 58(1), 1-6. https: //doi.org/10.1007/s12599-015-0409-x 